\title{
Identification of clonally rearranged $T$-cell receptor beta chain genes in HTLV-I carriers as a potential instrument for early detection of neoplasia
}

M.M. Sales ${ }^{1}$, C.N.A. Bezerra ${ }^{2}$, Y. Hiraki ${ }^{2}$, N.B. Melo ${ }^{3}$ and N.A. Rebouças ${ }^{2}$

\author{
${ }^{1}$ Serviço de Hematologia, Divisão de Laboratório Central, Departamento de Patologia, \\ Hospital das Clínicas, São Paulo, SP, Brasil \\ ${ }^{2}$ Departamento de Fisiologia e Biofísica, Instituto de Ciências Biomédicas, \\ Universidade de São Paulo, São Paulo, SP, Brasil \\ ${ }^{3}$ Fundação Pró-Sangue, Hemocentro de São Paulo, São Paulo, SP, Brasil
}

\footnotetext{
Correspondence

N.A. Rebouças

Departamento de Fisiologia e

Biofísica, ICB, USP

Av. Prof. Lineu Prestes, 1524

05508-900 São Paulo, SP

Brasil

Fax: +55-11-3091-7285

E-mail: nancy@icb.usp.br

Research supported by FAPESP

(No. 99/02574-5).

The present address of N.B. Melo is Laboratório Atalaia, Goiânia, GO, Brasil.
}

Received October 14, 2004 Accepted March 9, 2005

\begin{abstract}
We analyzed the genetic recombination pattern of the T-cell receptor beta-chain gene (TCR-beta) in order to identify clonal expansion of T-lymphocytes in 17 human T-lymphotropic virus type I (HTLV-I)-positive healthy carriers, 7 of them with abnormal features in the peripheral blood lymphocytes. Monoclonal or oligoclonal expansion of T-cells was detected in 5 of 7 HTLV-I-positive patients with abnormal lymphocytes and unconfirmed diagnosis by using PCR amplification of segments of TCR-beta gene, in a set of reactions that target 102 different variable $(\mathrm{V})$ segments, covering all members of the $24 \mathrm{~V}$ families available in the gene bank, including the more recently identified segments of the Vbeta- 5 and Vbeta- 8 family and the two diversity beta segments. Southern blots, the gold standard method to detect T-lymphocyte clonality, were negative for all of these 7 patients, what highlights the low sensitivity of this method that requires a large amount of very high quality DNA. To evaluate the performance of PCR in the detection of clonality we also analyzed 18 leukemia patients, all of whom tested positive. Clonal expansion was not detected in any of the negative controls or healthy carriers without abnormal lymphocytes. In conclusion, PCR amplification of segments of rearranged TCR-beta is reliable and highly suitable for the detection of small populations of clonal T-cells in asymptomatic HTLV-I carriers who present abnormal peripheral blood lymphocytes providing an additional instrument for following up these patients with potentially higher risk of leukemia.
\end{abstract}

Key words

- Human T-lymphotropic

virus 1

- Leukemia

- Oligoclonal bands

- T-cell receptor beta chain

- Polymerase chain reaction

- Adult T-cell

leukemia/lymphoma

\section{Introduction}

Human T-lymphotropic virus type I (HTLV-I) is the etiologic agent of adult T-cell leukemia/lymphoma (ATLL). It was in 1973 that ATLL, a previously unknown disease, was recognized in Japan (1). In 1980, the causal relationship between ATLL and HTLV- 
I was demonstrated (2). A mature T-cell non-Hodgkin's lymphoma, ATLL, is characterized by a leukemia phase presenting circulating activated CD4+/CD25+ T-cells. The HTLV-I infection has a wide distribution (3) with major endemic foci in the Caribbean $(4,5)$ and southern Japan (6). Important endemic foci are also observed in South America, including Brazil, where the most important focus is in Salvador (7-11). The common routes of transmission are motherto-child, blood transfusion and sexual activity, emphasizing the impact of HTLV-I-related diseases on public health (12).

Since HTLV-I was identified as the etiologic agent of ATLL, diversity in clinical features of the disease has been observed, resulting in a division of the ATLL spectrum into several subtypes. Shimoyama (13) defined four clinical subtypes of ATLL (acute, chronic, smoldering, and lymphoma type), following widely accepted criteria. The prognoses of prototype ATLL (acute type) and of the lymphoma type are both poor, while those of the chronic and smoldering subtypes are generally much better. Distinguishing between subtypes is often difficult at the time of diagnosis. In general, diagnosis of the chronic or smoldering type is only made after several months of evaluation without treatment. On the other hand, due to the rapid deterioration seen in cases of ATLL, patients with the acute type usually die before receiving adequate treatment (14).

After infection with HTLV-I, there is a long latent period before the onset of ATLL. The estimated interval between infection and malignancy is 20 to 30 years (15). During this latency period, infected cells are maintained in a balance between expansion and death, until this balance is eventually lost. Integration of HTLV-I provirus into the genome of the infected cells occurs at random locations, and identification of the integration site may serve as a marker for the clonal origin of the expanded cell populations. The profile of HTLV-I proviral DNA integration progresses from an undetectable state or polyclonal pattern, in which no cell population expands sufficiently to be detected, to oligoclonality or monoclonality during malignant transformation. Leukemia cells are usually monoclonal with respect to proviral integration, which is evidence that they originated from a single infected cell (16). Detection of clonal proliferation of infected cells, therefore, might indicate a pre-leukemia phase (17).

The cells that are typically HTLV-I-infected (malignant) are $\mathrm{CD} 2+/ \mathrm{CD} 3+/ \mathrm{CD} 4+/$ CD5+/CD25+ and CD7-/CD8- cells. In addition, T-cell receptor (TCR)-alpha/beta is usually expressed. However, a conclusive diagnosis cannot be made by the identification of this immunophenotype alone. The presence in the blood of large flower-like cells with lobulated nuclei has been viewed as pathognomonic of ATLL (15). However, the clonal proliferation of cells with integrated provirus is considered to be the definitive diagnostic parameter. In all types of ATLL, the monoclonal integration of the HTLV-I proviral DNA into tumor cells can be detected by Southern blotting (18).

The use of a more sensitive method than Southern blot to detect either clonal evolution or a change in the clonal pattern in an earlier phase may lead to a therapeutic approach that would avert aggressive crises from indolent ATLL, as well as prevent the first outbreak of ATLL in HTLV-I carriers (18). We propose that PCR amplification of the rearranged TCR-beta gene in order to detect clonal expansion of HTLV-I-infected T-cells would be a convenient method for detecting incipient clonal proliferation of infected cells. The TCR profile is variable in normal T-cell populations and becomes clonal in full-blown leukemia. In the present study, we used PCR to evaluate the rearrangement pattern of TCR-beta genes in order to detect early clonal proliferation in HTLV-I-positive patients for whom the diagnosis of ATLL was inconclusive. 


\section{Patients and Methods}

\section{Patients}

Blood samples were obtained from 17 patients identified as HTLV-I carriers during routine screening of blood donors. All presented circulating antibodies to HTLV-I proteins, and the results of a commercial ELISA were further confirmed by Western blot. All patients were also clinically asymptomatic and presented normal hepatic and renal function. Seven of these patients presented abnormal T-cells without providing any clear evidence of ATLL, and they were selected to constitute the primary study group (group I). The selection parameters included abnormal (but not "flower-like") cell morphology and increased expression of CD25 in T-lymphocytes, as evaluated by flow cytometry.

As a positive control group, we also included 18 patients with neoplasms of circulating T-cells and designated them group II. Of these, 5 had acute ATLL, 3 had chronic ATLL, 4 had T-cell large granular lymphocytic leukemia, 2 had mycosis fungoides/Sézary syndrome, and 4 had peripheral T-cell lymphoma, unspecified. The final diagnosis was always established according to the criteria defined by the World Health Organization Classification of Tumors (19). As a negative control, we included 9 normal blood donors and $10 \mathrm{HTLV}$ I carriers without abnormal lymphocytes (group III).

All procedures were approved by the Ethics Committee of Hospital das Clínicas da Universidade de São Paulo and Fundação Hemocentro do Estado de São Paulo, and all patients included in this study gave written informed consent.

\section{Methods}

Hematology and flow cytometry. The differential leukocyte count was performed using an automated analyzer and under light microscopy, with a special focus on lymphocyte morphology. Monoclonal antibodies to $\mathrm{CD} 3, \mathrm{CD} 4, \mathrm{CD} 5, \mathrm{CD} 7, \mathrm{CD} 8, \mathrm{CD} 16$, CD19, CD25, CD56, TCR-alpha/beta and TCR-gamma/delta, from Becton Dickinson Immunocytometry Systems (San Jose, CA, USA), were used to enumerate the subsets of lymphocytes by flow cytometry.

Multiplex PCR. DNA was extracted from all 44 blood samples and purified by standard methods. High molecular weight $(>50 \mathrm{~kb}$ ) DNA was obtained. The samples were quantified by spectrophotometry.

The rearrangement pattern in the TCRbeta chain gene and the binding sites of the primers have been described by Zemlin et al. (20) and are briefly presented in the Results section of the present paper. We performed a screening PCR employing the amplification parameter described by these investigators and using the enzyme Ampli-Taq Gold (Applied Biosystems, Foster City, CA, USA), which provides a "hot-start" PCR, together with $150 \mathrm{ng}$ DNA. For the 12 screening PCRs, the sense primers in four separate oligonucleotide mixtures (A, B, C, and D), bind to 24 variable families of TCR-beta. Two of the antisense primers (named Jbeta 1-e and Jbeta 2-e) match the two introns downstream of the Jbeta 1 and Jbeta 2 clusters, respectively. The third antisense primer, Jbeta 1-i, hybridizes to an intron region between Jbeta 1.3 and Jbeta 1.4 (Figure 1). Each of the four sense primer mixes was combined with each of the three antisense primers. These primer combinations can amplify fragments of defined size ranges from 110 to $1210 \pm 30 \mathrm{pb}$.

The second confirmatory PCR employs only the successful sense primer mix used with the Jbeta-specific antisense primers in 10 individual reactions. The second PCR results in short amplicons between 70 and $100 \mathrm{bp}$, and a distinct band can be distinguished from a smear over $20 \mathrm{bp}$ due to polyclonal rearrangement of the background (20). When the TCR-beta rearrangement 
occurred with the joining segments Jbeta 1.3, Jbeta 1.6 and Jbeta 2.7, the first PCR was already conclusive, and the second PCR was unnecessary.

As previously reported (20), the primer combination mix C/Jbeta 1-i can amplify a 1560-bp fragment of the germline sequence between Dbeta 1 and Jbeta 1. The generation of this amplicon served as an indicator of the number of germline cells in our samples. All PCR products were analyzed by $8 \%$ polyacrylamide gel electrophoresis.

Southern blot. For Southern blotting, 20 $\mu \mathrm{g}$ genomic DNA was fully digested with either EcoRI or HindIII restriction enzymes. The DNA fragments were separated by electrophoresis on $0.7 \%$ agarose gel and blotted onto a Zeta-Probe ${ }^{\circledR}$ nylon membrane (BioRad Laboratories, Hercules, CA, USA).

The membranes were probed with fluorescein-labeled fragments of DNA, previously amplified by PCR, using specific primers for the Jbeta 1 and Jbeta 2 segments of the human TCR-beta gene as described previously (21). The amplicons were cloned in pGEM-T $^{\circledR}$ (Promega, Madison, WI, USA) and sequenced using the BigDye Reaction kit (Applied Biosystems) and an Applied Biosystems ABI prism ${ }^{\circledR} 310$ genetic analyzer. The amplified segments of the TCR-beta gene were labeled with biotin using the Gene Images Random Prime Labeling kit (Amersham, Uppsala, Sweden). The detection system was chemiluminescence blotting for nucleic acid (DAKO, Glostrup, Denmark).

\section{Results}

\section{Morphology and immunophenotyping}

Table 1 displays an analysis of the proportion of abnormal non-"flower-like" lymphocytes, CD3+, CD4+, CD8+, and CD25+ lymphocytes, and the CD4/CD8 ratio. In addition to abnormal lymphocytes, some patients presented an increased proportion of
CD25+ lymphocytes, and one patient presented an elevated CD4/CD8 ratio. All patients were clinically asymptomatic.

\section{TCR-beta PCR}

In order to detect the pattern of TCR-beta rearrangement, we performed PCRs in which we used the primers designed by Zemlin et al. (20). The binding sites of the primers used for the screening PCR are detailed in Figure 1. The combination of 4 mixes of sense primers and 3 antisense primers resulted in 12 different reactions. Depending on the rearranged Jbeta segment, these 12 primer combinations could lead to amplicons of determined sizes ranging from $110 \pm 30$ to $1210 \pm 30$ bp (20). For monoclonal T-cell proliferation with one rearranged allele, the allele-specific amplicon dominates among weak bands generated by the polyclonal background. The confirmatory PCR was performed only with the successful sense primer mix and with all 10 Jbeta specific antisense primers (10 reactions). Zemlin et al. (20) did not design specific primers for all of the 13 joining regions because Jbeta 1.3, 2.6 and 2.7 segments already lead to small amplicons in the screening PCR, identifying the prevailing clone and, in these cases, obviating the need for a confirmatory PCR.

Samples from all 7 patients with an unconfirmed diagnosis were submitted to the first round of PCR to screen for clonal proliferation. When one or more of the twelve reactions resulted in amplicons within the expected size range, the confirmatory PCR was performed. After the second PCR round, we detected a strong band highly suggestive of clonal proliferation in 4 of 7 patients with an unconfirmed diagnosis (Figure 2A). All amplified fragments were from the Jbeta 1 cluster of TCR-beta, segments 1.1, 1.2, 1.2, and 1.1. In 2 patients, no clonal proliferation was observed; only a faint smear (no strong band) was seen. The screening PCR (first PCR) showed eight strong bands in the 


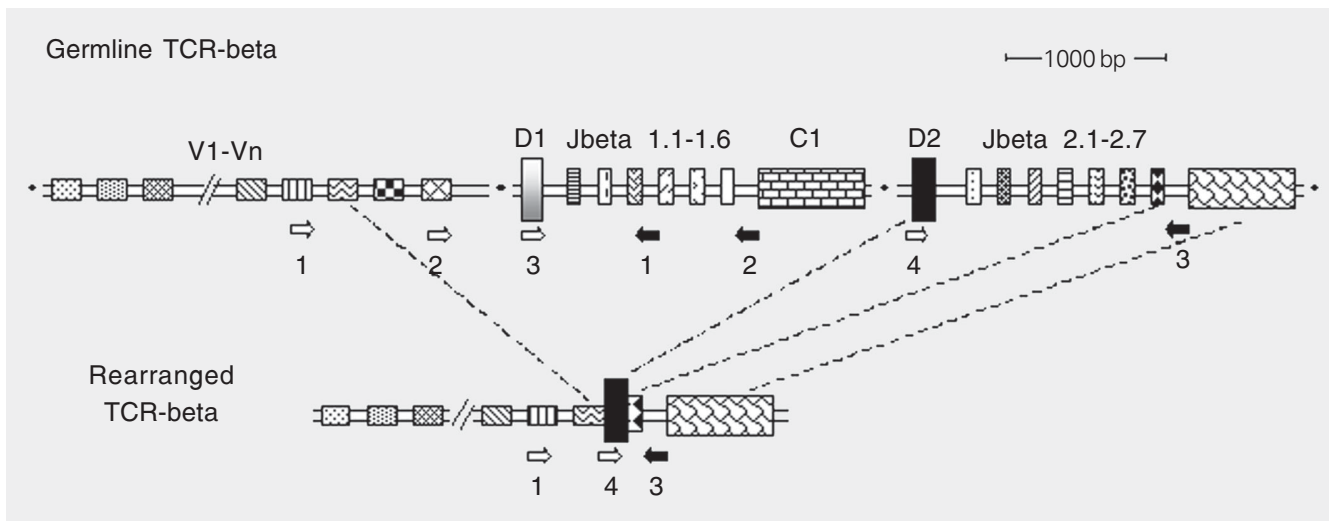

Table 1. Morphologic and immunophenotypic evaluation of peripheral blood from patients with an unconfirmed diagnosis of adult T-cell leukemia/lymphoma (group I).

\begin{tabular}{lccccccccc}
\hline Patient & Age & Sex & $\begin{array}{c}\text { Lymphocytes/ } \\
\mathrm{mm}^{2}\end{array}$ & $\begin{array}{c}\mathrm{AL} \\
(\%)\end{array}$ & $\begin{array}{c}\mathrm{CD} 3 \\
(\%)\end{array}$ & $\begin{array}{r}\mathrm{CD} 4 \\
(\%)\end{array}$ & $\begin{array}{c}\mathrm{CD} 8 \\
(\%)\end{array}$ & $\begin{array}{c}\mathrm{CD25} \\
(\%)\end{array}$ & $\begin{array}{c}\mathrm{CD} 4 / \mathrm{CD} 8 \\
\text { ratio }\end{array}$ \\
\hline 1 & 37 & $\mathrm{~F}$ & 1800 & 5 & 82 & 48 & 31 & $26^{*}$ & 15 \\
2 & 49 & $\mathrm{~F}$ & 2100 & 2 & 75 & 40 & 34 & 3 & 1.1 \\
3 & 61 & $\mathrm{~F}$ & 1800 & 6 & 57 & 37 & 28 & 8 & 1.3 \\
4 & 45 & $\mathrm{M}$ & 1300 & 2 & 65 & 42 & 21 & 7 & 2.0 \\
5 & 24 & $\mathrm{~F}$ & 3000 & 3 & 79 & 51 & 24 & $21^{*}$ & 2.1 \\
6 & 48 & $\mathrm{M}$ & 2100 & 2 & 71 & 50 & 23 & $15^{*}$ & 2.1 \\
7 & 48 & $\mathrm{M}$ & 3100 & 8 & 76 & 58 & 18 & 9 & $3.2^{*}$ \\
\hline
\end{tabular}

$\mathrm{AL}=$ abnormal lymphocytes; $\mathrm{F}=$ female; $\mathrm{M}=$ male.

${ }^{*}$ Increased compared to seronegative individuals (22).

expected size range for one patient. This suggests oligoclonal proliferation, which was confirmed by the second PCR round. The confirmatory PCR showed three strong bands referring to the joining segments Jbeta 1.1, Jbeta 1.2, and Jbeta 2.5 (Figure 2B).

The PCR screening of TCR-beta chains generated in samples of the 18 patients from group II showed monoclonal proliferation in 10 patients and oligoclonal proliferation in the remaining 8 . These results are presented in Table 2 and in Figure 3A, B, and C. The two PCR rounds were effective in detecting clonal proliferation of lymphocytes in all 18 patients presenting neoplasms.

The 19 individuals of group III (10 HTLVI carriers and 9 normal blood donors) tested negative for clonal proliferation in the two PCR rounds (data not shown).
Figure 1. Schematic presentation of the T-cell receptor (TCR)beta gene and a possible pattern of rearrangement. In the screening PCR, the sense primers (open horizontal arrows) were applied as four oligonucleotide mixtures, binding to all segments of the 24 variable (V) families available in GenBank and to the two diversity (D) beta segments. Two of the antisense primers (filled horizontal arrows) match to introns downstream of the Jbeta 1 and Jbeta 2 clusters (black arrows 2 and 3); the third antisense primer hybridizes to an intron between Jbeta 1.3 and Jbeta 1.4 (black arrow 1).

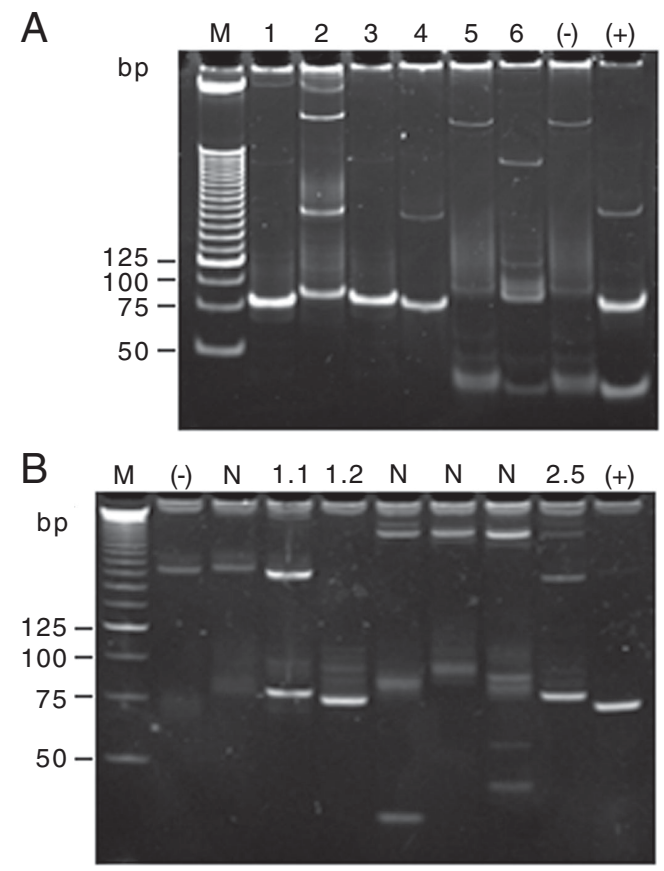

Figure 2. Second, confirmatory PCR for identification of junction segments used in the rearrangement of the TCR-beta gene. $A$, Monoclonal rearrangement was identified in patients $1,2,3$, and 4 , and the joining fragments belong to the Jbeta 1 cluster (segments 1.2, $1.2,1.2$, and 1.2, respectively). $B$, Patient number 7 presented an oligoclonal pattern of rearrangement, identified by the three strong bands observed in the lanes labeled 1.1 and 1.2 (in the Jbeta 1 cluster), and 2.5 (in the Jbeta 2 cluster). $M=$ marker of DNA size; bp = base pairs; $(+)=$ positive control; $(-)=$ negative control; $\mathrm{N}=$ negative result, or polyclonal. 


\section{Southern blot}

In order to demonstrate clonal expansion in the leukemia patients and as a counterpoint to PCR results from the patients with inconclusive diagnoses, Southern blots were performed. The germline patterns of Southern blotting of EcoRI- and HindIII-digested DNA, probed with Jbeta 1 and Jbeta 2 probes, is depicted in Figure 4A and B. Figure 4C shows the hybrid- ization pattern from a leukemia patient. In healthy individuals or in patients with mild polyclonal proliferation of T-lymphocytes, only the germ line bands were expected to be observed. In patients with monoclonal or oligoclonal proliferation, one or more bands, respectively, are expected in addition to the germ line bands, although the latter are not always visible because the germ line cells in the sample can be in very low concentrations.

Table 2. Diagnosis of the 18 leukemic patients included as positive controls (group II).

\begin{tabular}{rrc}
\hline Patient & Etiologic diagnosis & $\begin{array}{c}\text { TCR-beta junctions identified } \\
\text { by PCR in the clonally } \\
\text { expanded lymphocytes }\end{array}$ \\
\hline 1 & Peripheral T-cell lymphoma, unspecified & $1.5 / 1.6$ \\
2 & Peripheral T-cell lymphoma, unspecified & 1.2 \\
3 & Peripheral T-cell lymphoma, unspecified & 2.3 \\
4 & Peripheral T-cell lymphoma, unspecified & $1.4 / 2.3$ \\
5 & Mycosis fungoides/Sézary syndrome & 1.1 \\
6 & Mycosis fungoides/Sézary syndrome & $1.1 / 1.2$ \\
7 & Chronic ATLL & 2.6 \\
8 & Chronic ATLL & $1.5 / 1.1$ \\
9 & Chronic ATLL & 1.5 \\
10 & Chronic ATLL & 1.3 \\
11 & Chronic ATLL & 1.1 \\
12 & Chronic ATLL & $1.1 / 1.5 / 2.5$ \\
13 & Chronic ATLL & $1.5 / 1.1 / 1.2$ \\
14 & Chronic ATLL & $1.1 / 1.2$ \\
15 & T-cell large granular lymphocyte leukemia CD8+ & 1.2 \\
16 & T-cell large granular lymphocyte leukemia CD8+ & 1.1 \\
17 & T-cell large granular lymphocyte leukemia CD8+ & 1.2 \\
18 & T-cell large granular lymphocyte leukemia CD8+ & $1.4 / 1.5(?)$ \\
\hline
\end{tabular}

(?) = ambiguous beta junction. ATLL = adult T-cell leukemia/lymphoma.

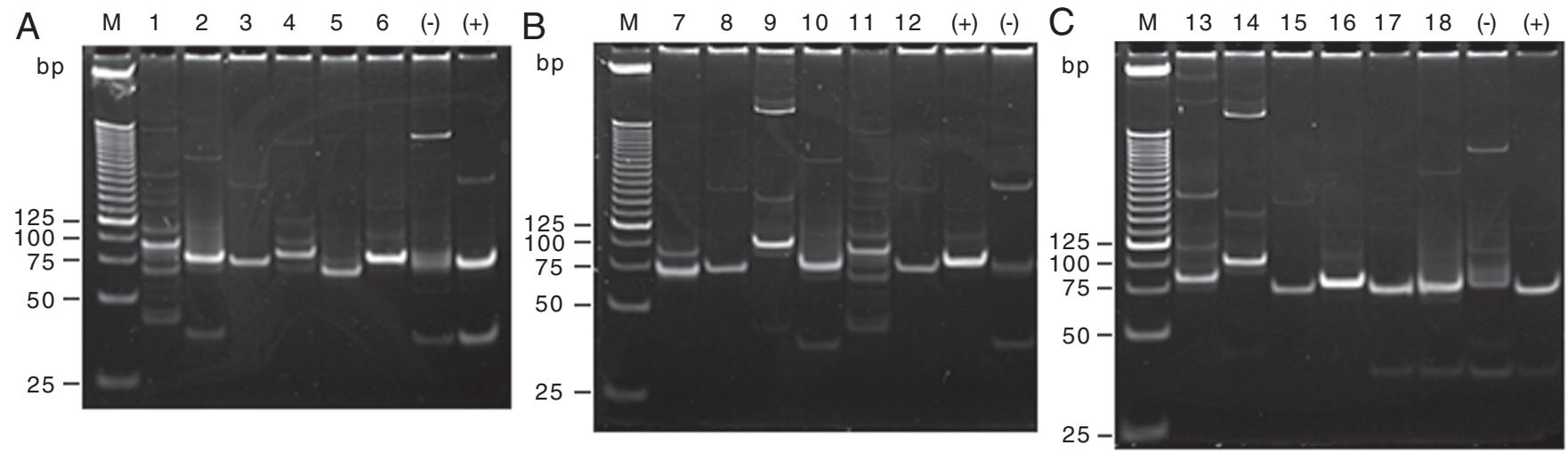

Figure 3. Confirmatory PCR for clonal rearrangement detection in leukemic patients. Panels $A, B$ and $C$ present the results of the confirmatory PCR for clonal rearrangement detection in the 18 leukemic patients (A: patients 1-6; B: patients 7-12; C: patients 13-18). Some patients presented an oligoclonal pattern of rearrangement, and only the strongest band was selected for presentation. $\mathrm{M}=$ marker of DNA size; bp = base pairs; $(+)=$ positive control; $(-)=$ negative control; $\mathrm{N}=$ negative result, or polyclonal. 
We tested the 7 patients with an unconfirmed diagnosis by Southern blot. As shown in Figure 4D, all of the Southern blots from these patients showed only the germ line hybridization pattern. In our positive control group, only 9 of the 18 patient samples yielded sufficient DNA for Southern blotting. These 9 samples were hybridized with the Jbeta 1 and Jbeta 2 probes, and all showed bands corresponding to the joining cluster previously identified by PCR (data not shown).

\section{Discussion}

HTLV-I transforms the human primary T-cells CD4+, CD8-, DR+, and CD25+ both in vitro and in vivo. The oncogenic mechanisms of HTLV-I have many obscure features. When a cell is infected, the HTLV-I genome integrates into the genome of the host cell in a random process (23). The roughly $9-\mathrm{kb}$ sequence of the HTLV-I genome encodes structural proteins such as Gag and Env, enzymes such as reverse transcriptase, integrase and protease, and regulatory proteins such as Tax, Rex, p21XIII, p12, and others derived from the $\mathrm{pX}$ region of the genome $(15,24,25)$. The long terminal repeats located at the two ends ( 5 and $3^{\prime}$ ) of the viral genome contain the viral promoter and other regulatory elements. The Tax protein is one of the most important elements for the transcriptional activation of the viral genome. The delicate equilibrium between the positive and negative effects of Tax and Rex on each other, on other viral products, and on other cellular proteins is one of the main determinants of the rate of viral replication.

Primary cultures of T-cells from HTLVI-infected individuals most often yield an activated IL-2-dependent (immortalized), rather than IL-2-independent (transformed) T-cell line (25). However, repeated culture of primary T-cells from HTLV-I-infected individuals with normal human T-cells often results in a transformed T-cell line, suggesting that malignant transformation does not occur until after the clonal selection $(26,27)$. As previously discussed, leukemia develops after a long latent period and in only a small portion of infected individuals. Therefore, cumulative defects in the infected host cells, combined with immune suppression, seem to be responsible for the leukemia phenotype that appears only several years after viral infection (15).

Since HTLV-I integrates its provirus randomly into host chromosomal DNA, identification of a cell population with a unique insertion site indicates the clonal proliferation of the HTLV-I-infected cells. Despite its low sensitivity, Southern blot analysis using labeled segments of the proviral DNA as probes has been used to detect monoclonal integration of the provirus. Takemoto et al. (22) proposed inverse PCR as a way of assessing the clonality of integrated HTLV-I proviral DNA. One of the problems with the inversePCR approach is that the provirus suffers partial deletions in a significant number of the infected cells, especially in patients with a poor prognosis (28). Therefore, it is uncertain whether the specific HTLV-I primers will anneal during PCR. In addition, the inverse-PCR method is too complex to serve as a routine diagnostic test, especially if we consider the crucial step of DNA ligation to circularize the fragments. In our experience
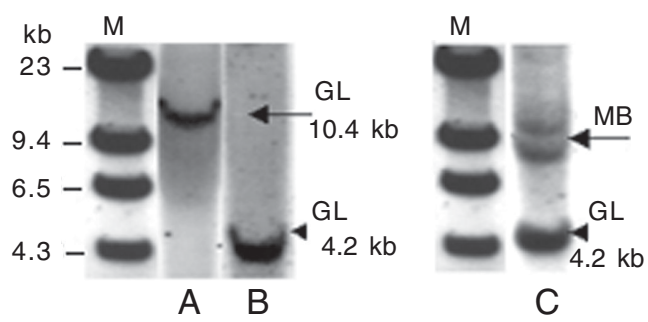

Figure 4. Southern blot of EcoRI fully digested DNA hybridized with Jbeta 1 or Jbeta 2 specific probe. $A$, Hybridization pattern in Jbeta 1 germ cells; $B$, hybridization pattern in Jbeta 2 germ cells; $C$, hybridization pattern observed in a sample from a patient with leukemia using a probe for the Jbeta 2 segment. $M=$ marker of DNA size; $\mathrm{kb}=$ kilobase pairs; $\mathrm{MB}=$ monoclonal band; $\mathrm{GL}=$ germline band. 
the ligation reaction was very unpredictable (data not shown), whereas PCR amplification of segments of the rearranged TCR-beta gene proved to be more feasible than the detection of the provirus insertion by the inverse-PCR method proposed by Takemoto. The PCR amplification of segments of the rearranged TCR genes might therefore be considered the method of choice for detection of incipient clonality in HTLV-I carriers with suspicious findings in laboratory test results. The two rounds of PCR amplification of TCR-beta gene segments, as proposed by Zemlin et al. (20), detected clonal proliferation of T-lymphocytes. In the group of our 7 patients with abnormal lymphocytes in their peripheral blood, this method revealed the proliferation to be monoclonal in 4 patients and oligoclonal in one patient, although these lymphocytes were identified in Southern blots as polyclonal (designated germ line in the Results section). The TCR-beta PCR assay is fast and reliable, and the specific clonal insertion of HTLV-I can be confirmed separately.

The main limitation of PCR-based detection of clonal TCR rearrangements is the risk of false-positive results due to 'background' amplification of rearranged TCR-beta genes in polyclonal reactive T-lymphocytes. In HTLV-I carriers, significant reactive proliferation of T-lymphocytes destined to eliminate infected cells expressing viral proteins should occur. This reactive proliferation must not be taken as evidence for malignant transformation of HTLV-I-infected cells. However, it is important to emphasize that in our study none of the healthy carriers or blood donors presented any evidence of clonal rearrangement of TCR-beta. Other investigators have also demonstrated the specificity of a clonal TCR rearrangement for malignant and pre-malignant states. In these studies, none of the negative control individuals presented evidence of clonal lymphocyte proliferation, as evaluated by PCR amplification of segments of the rearranged TCR-beta gene
(29-31). Occasionally, patients with reactive T-lymphocytes have displayed an oligoclonal pattern, comprising only a few dominant clones, rather than a polyclonal rearrangement pattern. However, repeated independent PCR assays have clearly demonstrated that the dominant clones differed from each other among various PCRs at different times (31). Ohshima et al. (16) used Southern blots to analyze 16 healthy HTLV-I-positive patients and detected oligoclonal TCR-beta rearrangement in all 16. However, this finding is unusual in the literature, and we observed no such pattern in our patients. One possible explanation for the high incidence of oligoclonal TCR-beta rearrangement in carriers reported by Ohshima et al. (16) is incomplete digestion of the DNA samples with the restriction enzyme used in Southern blotting.

The identification of T-cell clonality in peripheral blood samples from HTLV-I-infected patients with abnormal peripheral blood lymphocytes may be of important diagnostic value. Over-interpretation of dominant PCR products with respect to the diagnosis of malignancy may be avoided by repeated independent PCR determinations and application of high-resolution separation techniques, such as DNA sequencing (32). Reactive lymphoid tissues may present dominant PCR products that vary, whereas, under malignant conditions, dominant PCR products are always exactly reproducible.

The PCR amplification of segments of rearranged TCR-beta previously described by Zemlin et al. (20) and used, with minor modifications, in this study is reliable and highly suitable for the detection of small populations of clonal T-cells in healthy HTLVI carriers that present abnormal lymphocytes in peripheral blood. These patients must be carefully monitored in order to detect early signals of malignant transformation. The low background of the second round of the TCRbeta PCR products enables direct sequencing. This may be extremely useful for the surveillance of the persistence of the same 
clone for an extended period, which would provide clearer evidence of the high possibility of developing ATLL.

\section{Acknowledgments}

We thank Dr. Marcelo Cliquet, Chief of the Divisão de Medicina Transfusional until May 2002. We are also grateful to Dr. Bryan Eric Strauss, from Instituto do Coração, Faculdade de Medicina, Universidade de São Paulo, São Paulo, SP, Brazil, for carefully reading the manuscript.

\section{References}

1. Yodoi J, Takatsuki K \& Masuda T (1974). Two cases of T-cell chronic lymphocytic leukemia in Japan (Letter). New England Journal of Medicine, 290: 572-573.

2. Poiesz BJ, Ruscetti FW, Gadzar AF, Bunn PA, Minna D \& Gallo RC (1980). Detection and isolation of type C retrovirus particles from fresh and cultured lymphocytes of a patient with cutaneous T-cell lymphoma. Proceedings of the National Academy of Sciences, USA, 77: 7415-7419.

3. Tajima K (1998). Worldwide distribution of HTLV. Japanese Journal of Cancer Research, 89: 16-20.

4. Manns A \& Blattner WA (1991). The epidemiology of the human Tcell lymphotrophic virus type I and type II: etiologic role in human disease. Transfusion, 31: 67-75.

5. Rouet F, Rabier R, Foucher C, Chancerel B, Agis F \& Strobel M (1999). Geographical clustering of human T-cell lymphotropic virus type I in Guadeloupe, an endemic Caribbean area. International Journal of Cancer, 81: 330-334.

6. Takatsuki K, Matsuoka M \& Yamaguchi K (1996). Adult T-cell leukemia in Japan. Journal of Acquired Immune Deficiency Syndromes and Human Retrovirology, 13 (Suppl I): S15-S19.

7. Dourado I, Alcantara LC, Barreto P, da Gloria Teixeira M \& GalvãoCastro B (2003). HTLV-I in the general population of Salvador, Brazil: a city with African ethnic and sociodemographic characteristics. Journal of Acquired Immune Deficiency Syndromes, 34: 527-531.

8. Nogueira CM, Cavalcanti M, Schechter M \& Ferreira Jr OC (1996). Human T lymphotropic virus type I and II infections in healthy blood donors from Rio de Janeiro, Brazil. Vox Sanguinis, 70: 4748.

9. Ferreira Junior OC, Vaz RS, Carvalho MB, Guerra C, Fabron AL, Rosemblit J \& Hamerschlak N (1995). Human T-lymphotropic virus type I and type II infections and correlation with risk factors in blood donors from São Paulo, Brazil. Transfusion, 35: 258-263.

10. Proietti FA, Lima-Martins MV, Passos VM, Brener S \& CarneiroProietti AB (1994). HTLV-I/II seropositivity among eligible blood donors from Minas Gerais State, Brazil. Vox Sanguinis, 67: 77.

11. Britto AP, Galvão-Castro B, Straatmann A, Santos GF \& TavaresNeto J (1998). HTLV-I/II infection in the State of Bahia. Revista da Sociedade Brasileira de Medicina Tropical, 31: 35-41.

12. Manns A, Hisada M \& La Grenade L (1999). Human T-lymphotropic virus type I infection. Lancet, 353: 1951-1958.

13. Shimoyama M (1991). Diagnostic criteria and classification of clinical subtype of adult T-cell leukemia/lymphoma. A report from the Lymphoma Study Group (1984-87). British Journal of Haematology, 79: 428-437.

14. Shimoyama M, Ota K, Kikuchi M, Yunoki K, Konda S, Takatsuki K,
Ichimaru M, Tominaga S, Tsugane S \& Minato K (1991). Major prognostic factors of patients with adult T-cell leukemia-lymphoma: a cooperative study. Lymphoma Study Group (1984-1987). Leukemia Research, 15: 81-90.

15. Franchini $\mathrm{G}$ (1995). Molecular mechanisms of human T-cell leukemia/lymphotropic virus type I infection. Blood, 86: 3619-3639.

16. Ohshima K, Mukai Y, Shiraki H, Suzumiya J, Tashiro K \& Kikuchi M (1997). Clonal integration and expression of human T-cell lymphotropic virus type $\mathrm{I}$ in carriers detected by polymerase chain reaction and inverse PCR. American Journal of Hematology, 54: 306-312.

17. Tamiya S, Matsuoka M, Takemoto $S$ et al. (1995). Adult T cell leukemia following HTLV-I-associated myelopathy/tropical spastic paraparesis: case reports and implication to the natural course of ATL. Leukemia, 9: 1768-1770.

18. Yoshida M, Seiki M, Yamaguchi K \& Takatsuki K (1984). Monoclonal integration of human $\mathrm{T}$-cell leukemia provirus in all primary tumors of adult T-cell leukemia suggests causative role of human T-cell leukemia virus in the disease. Proceedings of the National Academy of Sciences, USA, 81: 2534-2537.

19. Jaffe ES \& Ralfkiaer E (2001). Mature T-cell and NK-cell neoplasms. In: Jaffe ES, Harris NL, Stein H \& Vardiman JW (Editors), World Health Organization Classification of Tumors. Pathology and Genetics of Tumors of Haematopoietic and Lymphoid Tissues. IARC Press, Lyon, France, 191-194.

20. Zemlin M, Hummel M, Anagnostopoulos I \& Stein H (1998). Improved polymerase chain reaction detection of clonally rearranged T-cell receptor beta chain genes. Diagnostic Molecular Pathology, 7: $138-145$

21. Langerak AW, Wolvers-Tettero IL \& van Dongen JJ (1999). Detection of $\mathrm{T}$ cell receptor beta (TCRB) gene rearrangement patterns in $\mathrm{T}$ cell malignancies by Southern blot analysis. Leukemia, 13: 965974.

22. Takemoto S, Matsuoka M, Yamaguchi K \& Takatsuki K (1994). A novel diagnostic method of adult T-cell leukemia: monoclonal integration of human T-cell lymphotropic virus type I provirus DNA detected by inverse polymerase chain reaction. Blood, 84: 30803085 .

23. Welles SL, Tachibana N, Okayama A, Murai K, Shioiri S, Sagawa K, Katagiri K \& Mueller NE (1994). The distribution of T-cell subsets among HTLV-I carriers in Japan. Journal of Acquired Immune Deficiency Syndromes, 7: 509-516.

24. Hollsberg P (1999). Mechanisms of T-cell activation by human Tcell lymphotropic virus type I. Microbiology and Molecular Biology Reviews, 63: 308-333.

25. Johnson JM, Harrod R \& Franchini G (2001). Molecular biology and pathogenesis of the human T-cell leukaemia/lymphotropic 
virus type-1 (HTLV-1). International Journal of Experimental Pathology, 82: 135-147.

26. Hollsberg P, Wucherpfennig KW, Ausubel LJ, Calvo V, Bierer BE \& Hafler DA (1992). Characterization of HTLV-I in vivo infected T cell clones. IL-2-independent growth of nontransformed T cells. Journal of Immunology, 148: 3256-3263.

27. Franchini G, Mann DL, Popovic M, Zicht RR, Gallo RC \& WongStaal F (1985). HTLV-I infection of T and B cells of a patient with adult T-cell leukemia-lymphoma (ATLL) and transmission of HTLVI from B cells to normal T cells. Leukemia Research, 9: 1305-1314.

28. Tsukasaki K, Tsushima H, Yamamura M et al. (1997). Integration patterns of HTLV-I provirus in relation to the clinical course of ATL: frequent clonal change at crisis from indolent disease. Blood, 89: 948-956.

29. McCarthy KP, Sloane JP, Kabarowski JH, Matutes E \& Wiedemann LM (1992). A simplified method of detection of clonal rearrange- ments of the T-cell receptor-gamma chain gene. Diagnostic Molecular Pathology, 1: 173-179.

30. Bergman R, Faclieru D, Sahar D, Sander CA, Kerner H, Ben-Aryeh Y, Manov L, Hertz E, Sabo E \& Friedman-Birnbaum R (1998). Immunophenotyping and T-cell receptor gamma gene rearrangement analysis as an adjunct to the histopathologic diagnosis of mycosis fungoides. Journal of the American Academy of Dermatology, 39: 554-559.

31. Assaf C, Hummel M, Dippel E, Goerdt S, Muller HH, Anagnostopoulos I, Orfanos CE \& Stein H (2000). High detection rate of T-cell receptor beta chain rearrangements in T-cell lymphoproliferations by family specific polymerase chain reaction in combination with the GeneScan technique and DNA sequencing. Blood, 96: 640646.

32. Dippel E, Klemke D, Hummel M, Stein H \& Goerdt S (2001). T-cell clonality of undetermined significance. Blood, 98: 247-248. 